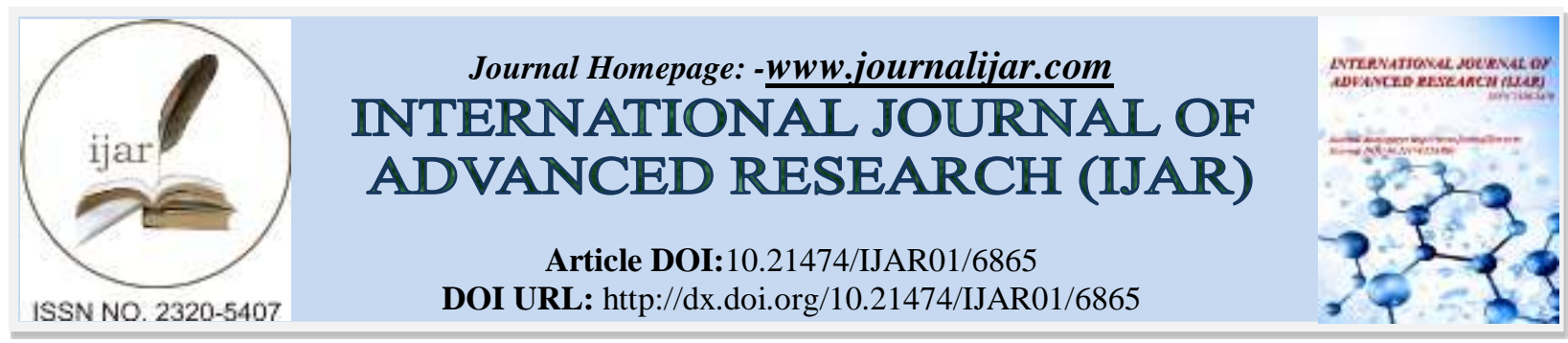

RESEARCH ARTICLE

\title{
EFFECTIVENESS OF COGNITIVE BEHAVIOR THERAPY ON ATTENTION DEFICIT HYPERACTIVITY DISORDER AMONG SCHOOL GOING CHILDREN - A PILLOT STUDY REPORT.
}

Sasikala. G and Dr. Prema. K.

\section{Manuscript Info}

(.........................

Manuscript History

Received: 06 February 2018

Final Accepted: 08 March 2018

Published: April 2018

Keywords:-

Cognitive Behaviour Therapy, Attention Deficit Hyperactivity Disorder, School Going Children.

\begin{abstract}
The prevalence of ADHD in school going children is estimated to be $3 \%$ to $7 \%$ and the disorder is more common in boys than girls. Quantitative - Evaluatory research study was conducted to find out the reliability and feasibility of the tool and 35 samples selected through purposive sampling technique from union school, Iyyappanthangal, kancheepuram district,Tamil Nadu. School going children from 6-12 years were selected as samples. ADHD was assessed by using Modified Vanderbilt ADHD Diagnostic Teacher Rating Scale. 35 samples were given cognitive behavior therapy for 3 sittings. Post-test was done after 3 weeks by using the same scale. The results revealed that the tools used, set criteria for sample selection the implementation of interventions were highly reliable and feasible for implementation.
\end{abstract}

Copy Right, IJAR, 2018,. All rights reserved.

\section{Introduction:-}

It is common for children, especially young school going children, to be active, energetic and exuberant and to flit from one activity to another as they explore their environment and its novelties. They are also notorious for getting bored easily with tasks that lack intrinsic appeal for them. Acting without much forethought and responding on impulse to events that occur around them, their emotional reactions to these events often readily apparent, are typical characteristics of young children.

School going period is the foundation for motor, cognitive, social, emotional, language development, and life- long learning, in any community parents and children constitute a priority group. In cheer number they comprise approximately $70 \%$ of the population in the developed countries.

Society holds widespread and deeply seated beliefs about the nature of self-control and moral conduct. Its members are quick to morally judge those who may fall short of the mark and behave in less than responsible fashion. Such impulsive children may both fascinate and repel us, causing us consternation about why they cannot seem to control their own behaviour, follow through on what they are told to do, and pay attention to getting ready for the future, and simultaneously shocking our sensibilities with their often heedless risk taking, disregard for others, devil-maycare attitudes, and hell-bent, seemingly self-destructive ways. As a result, it leads to Attention Deficit Hyperactive Disorder (ADHD).

Children who are excessively active, are unable to sustain their attention, and are deficient in their impulse control to a degree that is deviant for their developmental level are now given the clinical diagnosis of Attention Deficit Hyperactivity Disorder (ADHD) (American Psychiatric Association. 1994). 
Children with attention deficit hyperactivity disorder also grow up with stigma and negative feedback from others about their behaviour. As a result they may view themselves as stupid, frustrated, "messing up" helpless, and worthless (Krueger \& Kendall, 2001). The time the child starts school, symptoms of attention deficit hyperactivity disorder begins to interfere significantly with behavior and performance (Pary et al., 2002).

About 5\% of the population has ADHD. It occurs in families if a child has ADHD, the chance of a sibling having $\mathrm{ADHD}$ is $30 \%$. If a parent has $\mathrm{ADHD}$, the risk for a child may be as high as $25 \%$ to $50 \%$ (Harmon, 2000).

Objectives:-

To test the reliability - feasibility of the tool and to assess the effectiveness of cognitive behavior therapy on ADHD.

\section{Methodology:-}

Research Approach:-

Quantitative -Evaluatory research approach was used to assess the effectiveness of CBT on ADHD.

\section{Research Design:-}

One group pre-test post-test research design was used to assess the effectiveness of CBT on ADHD.

\section{Research Setting:-}

The study was conducted in union school, Iyyappanthangal, kancheepuram district,Tamil Nadu.

Research Population:-

School going children aged between 6-12 yrs in Kancheepuram district.

\section{Sample:-}

School aged children diagnosed as ADHD in union school, Iyyappanthangal, Kancheepuram district ,Tamil Nadu.

\section{Sample size:-}

The sample size is 35 as determined by power analysis.

\section{Sampling techniques:-}

Samples were selected using purposive sampling technique.

\section{Sampling criteria:-}

Inclusion Criteria:-

School going children aged between 6-12 Yrs.

\section{Exclusion Criteria:-}

1. School going children who are in long leave due to medical reason.

2. Parents of children who are not willing to participate / who are not given written consent.

\section{Tools and Description:-}

Part I: - It deals with Demographic details of Parent, Student \& Teacher.

Part II: - Modified Vanderbilt ADHD Diagnostic Teacher Rating Scale.

\section{Results and Discussion:-}

The reliability of the data collection tools were assessed by Split - Half method. The " $r$ " value was 0.95 . The score indicates high correlation and the tool were considered as highly reliable.

Data were analyzed by using paired " $\mathrm{T}$ " test, descriptive statistics, mean and standard deviation, inferential statistics for assessing the effectiveness of CBT on ADHD.

Table 1:- showed that Frequency and percentage distribution of pre-test and post-test level of inattentive among school children

Table 2:- showed that the Frequency and percentage distribution of pre-test and post-test level of hyperactivity among school children 
Table 3:- showed that the Comparison of pre-test and post inattentive score among school children.

Table 4:-showed that the Comparison of pre-test and post hyperactivity score among school children.

Chart 1:- showed that the Percentage distribution of pre-test and post-test level of inattentive among school children.

Chart 2:- showed that the Percentage distribution of pre-test and post-test level of hyperactivity among school children

Frequency and percentage distribution of pre-test and post-test level of inattentive among school children

\begin{tabular}{|l|c|c|c|c|c|c|}
\hline \multirow{2}{*}{ Inattentive } & \multicolumn{2}{c|}{ Mild } & \multicolumn{2}{c|}{ Moderate } & \multicolumn{2}{c|}{ Severe } \\
\cline { 2 - 7 } & No. & \% & No. & \% & No. & 0 \\
\hline Pretest & 16 & 45.71 & 19 & 54.29 & 0 & 0 \\
\hline Post Test & 18 & 51.43 & 17 & 48.57 & 0 & 0 \\
\hline
\end{tabular}

Frequency and percentage distribution of pre-test and post-test level of hyperactivity among school children

\begin{tabular}{|l|c|c|c|c|c|c|}
\hline \multirow{2}{*}{ Hyperactivity } & \multicolumn{2}{c|}{ Mild } & \multicolumn{2}{c|}{ Moderate } & \multicolumn{2}{c|}{ Severe } \\
\cline { 2 - 7 } & No. & \% & No. & \% & 0 & 0 \\
\hline Pretest & 23 & 65.71 & 12 & 34.29 & 0 & 0 \\
\hline Post Test & 24 & 68.57 & 11 & 31.43 & 0 & 0 \\
\hline
\end{tabular}

Comparison of pre-test and post inattentive score among school children

\begin{tabular}{|l|c|c|c|}
\hline \multicolumn{1}{|c|}{ Inattentive } & Mean & S.D & Paired 't' Value \\
\hline Pretest & 11.68 & 8.37 & $\mathbf{t}=\mathbf{2 . 3 0 7}$ \\
\hline Post Test & 11.20 & 8.00 & $\mathbf{p}=\mathbf{0 . 0 2 7}, \mathbf{S}^{*}$ \\
\hline
\end{tabular}

$* \mathrm{p}<0.05, \mathrm{~S}-$ Significant

Comparison of pre-test and post hyperactivity score among school children

\begin{tabular}{|l|c|c|c|}
\hline \multicolumn{1}{|c|}{ Hyperactivity } & Mean & S.D & Paired 't' Value \\
\hline Pretest & 10.91 & 7.80 & $\mathbf{t}=\mathbf{2 . 1 3 2}$ \\
\hline Post Test & 10.45 & 7.36 & $\mathbf{p}=\mathbf{0 . 0 4 0 , \mathbf { S } ^ { * }}$ \\
\hline
\end{tabular}

$* \mathrm{p}<0.05, \mathrm{~S}-$ Significant

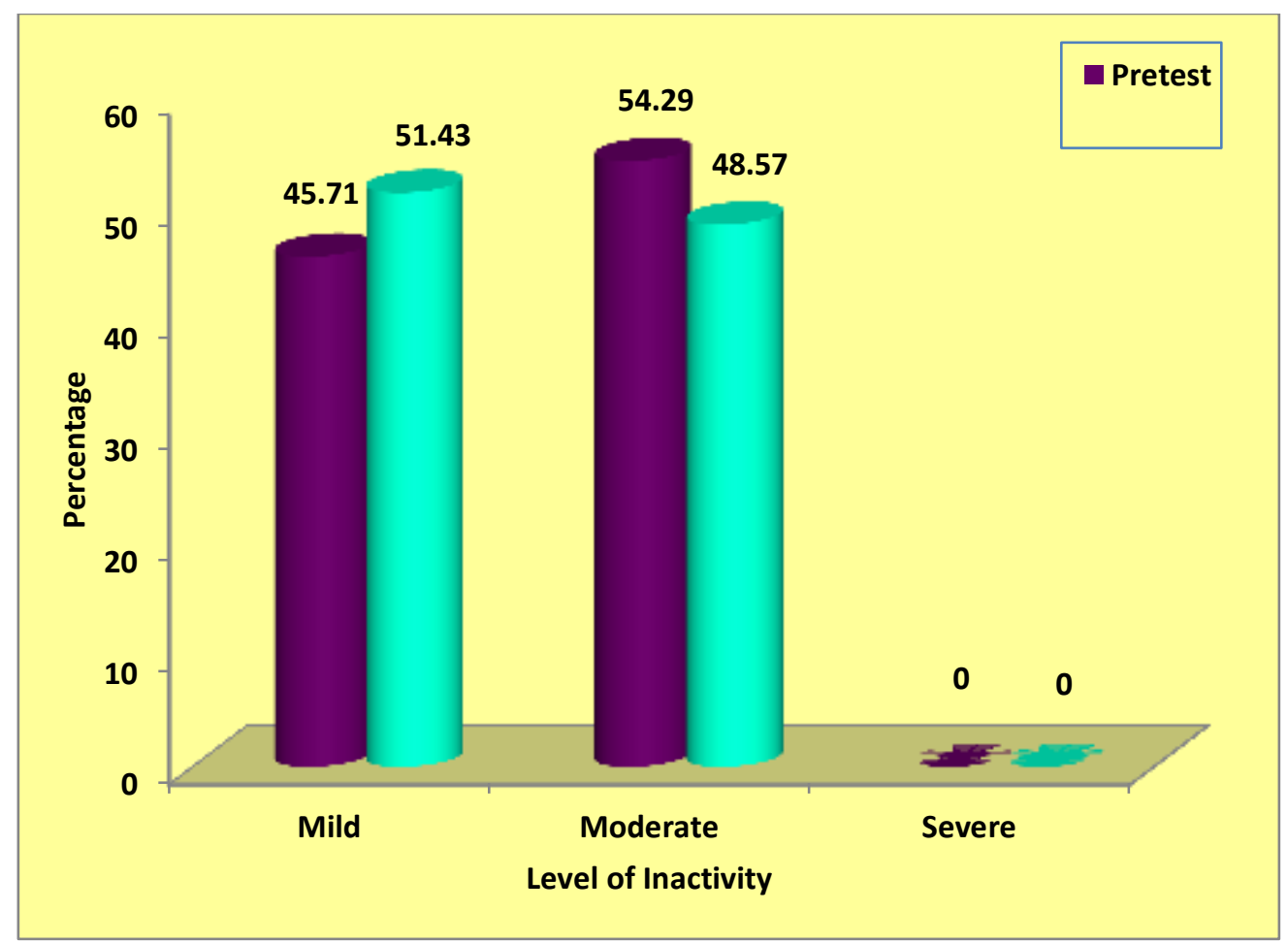

Percentage distribution of pretest and post-test level of inattentive among school children 


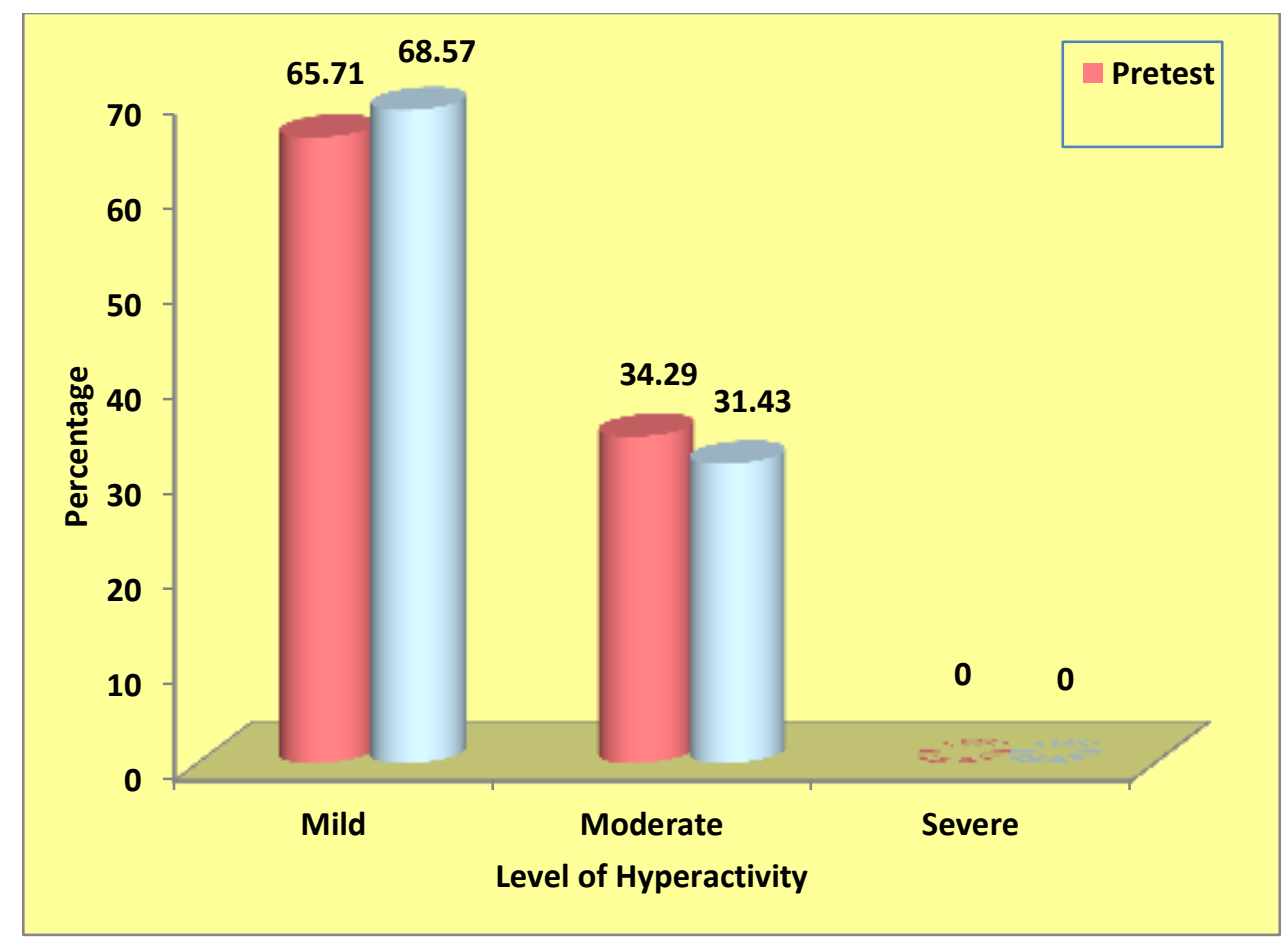

Percentage distribution of pretest and posts-test level of hyperactivity among school children

\section{Discussion:-}

The main focus of this study was to test the reliability and feasibility of the data collection tools and intervention and its acceptability and effectiveness in the level of ADHD among school going children. The results indicated that tools used were highly reliable.

The pilot study also showed that the sampling technique, set inclusion and exclusion criteria were appropriate for sample selection. The method of CBT selected and the proposed analytical measures were suitable for the study. The comparison between the pre-test and post test showed that there was a statistical significance. The overall plan was effective, feasible and practicable to be applied in the main study.

\section{Conclusion:-}

The pilot study on the effectiveness of CBT on ADHD for school going children. The Data collection tools used were reliable, feasible and appropriate to be applied to the samples in the main study And the CBT was effective in reducing the level of ADHD significantly among the school going children with ADHD.

\section{References:-}

1. Chang H.H et al., (2007). The process of assisting behavioural modification in a child with attention deficit by hyperactivity disorder. Journal of Nursing Research. 15(2), $147-155$.

2. Barbaresi et al., (2002). Primary care approach in the diagnosis and management on ADHD. Mayo Clinical Proceedings. $\underline{71}, 463-471$.

3. Danforth JS et al., (2006). The outcome of group parent training for families of children with ADHD and deficit / aggressive behaviour. Journals of Behaviour therapy experimental psychiatry. 37(3), 188 - 205.

4. Gupta, et al., (2001). Prevalence of behavioural problems in school going children. Indian Journal of Paediatrics. 68(4). $323-326$.

5. Ickowicz .A et al., (2006). Parent interview for child symptoms of ADHD and related disorders. Canadian Journal of Psychiatry. 51(5). 325 - 328.

6. Sailaxmi Gandhi (2002). Effectiveness of concentration enhancement therapy in inattentive, hypertensive children. Nursing Times. $24-27$. 